\title{
PENGARUH JENIS KECERDASAN TERHADAP HASIL BELAJAR TOPIK ALJABAR KELAS VIII MTSN SE-KOTA PADANGSIDIMPUAN
}

\author{
Ahmad Nizar Rangkuti dan Sojuangon Rambe \\ Dosen Fakultas Tarbiyah dan Ilmu Keguruan IAIN Padangsidimpuan \\ Email: nizarahmad1304@yahoo.com, and sojuangonr@gmail.com
}

\begin{abstract}
This research aims to explore the effect of the seven major kinds of human intelligence identified by Howard Gardner (1983) on students' ability to solve mathematical problems specifically in Algebra topic. This research involves about 115 participants randomly taken from whole tested population. Data collection was conducted by introducing test and questionnaire. The hypothesis examination resulted that hypothesis was accepted at index: $F_{\text {count }} 2,327>F_{\text {table }} 2,09$ in significance level $\alpha=0,05$. By using the Scheffe's formula, order of sequence of ability to solve algebra's problems based on the intelligence types was: Logicalmathematics $>$ Bodily-Kinesthetic $>$ Intrapersonal> Interpersonal $>$ Linguistics $>$ Spatial $>$ Musical.
\end{abstract}

Keywords: kinds of intelegence, multiple intelegence, mathematics, and Algebra.

\begin{abstract}
Abstrak
Penelitian ini bertujuan untuk mengeksplorasi pengaruh ketujuh jenis kecerdasan manusia menurut Howard Gardner (1983) dari kemampuan siswa dalam menyelesaikan masalah khususnya pada topik aljabar. Penelitian ini terdiri dari 115 responden yang diambil secara random dari populasi. Pengumpulan data dengan menggunakan test dan angket. Hasil uji hipotesis diperoleh dengan $F_{\text {hitung }}$ 2,327 $>F_{\text {tabel }}$ 2,09 pada taraf signifikansi $\alpha=0,05$. Dengan menggunakan uji Scheffe, urutan dari kemampuan menyelesaikan soal aljabar berdasarkan jenis kecerdasan adalah: Logika-matematika $>$ Kinestetik> Intrapersonal $>$ Interpersonal $>$ Linguistik $>$ Spasial $>$ Musika.
\end{abstract}

Kata Kunci: jenis kecerdasan, kecerdasan berganda, matematika, aljabar

\section{PENDAHULUAN}

Pencapaian hidup manusia berkaitan erat dengan potensi yang ada pada dirinya. Potensi itu bisa berupa minat dan talenta/bakat yang membuat seseorang mampu mencapai keunggulan dalam suatu bidang, jauh melebihi orang kebanyakan. Pada prinsipnya, jika suatu bidang kehidupan dijalani seseorang sesuai dengan minat dan bakatnya maka bidang tersebut akan bisa dilakoni dengan maksimal, jika sebaliknya maka tidak akan maksimal pula. Oleh 
karena itu pengenalan dan pengembangan manusia sesuai dengan potensinya menjadi faktor penentu kesuksesan yang tidak boleh diabaikan.

Pengembangan manusia dimanapun di bumi ini diserahkan kepada dunia pendidikan, tentu demikian pula di Indonesia. Pemerintah melalui UU. No 20 tahun 2003, tujuan pendidikan nasional adalah: Untuk memenuhi tanggung jawabnya dalam rangka mencapai sasaran yang tepat dan hasil yang optimal, maka pengenalan akan potensi anak didik merupakan hal yang niscaya dalam pengelolan pendidikan.

Upaya untuk itu sudah dilakukan oleh banyak ahli dan praktisi sampai berhasil menemukan sederetan faktor-faktor yang dianggap berpengaruh terhadap hasil belajar siswa. Dari faktor yang mempengaruhi hasil belajar siswa, maka rumusan masalah dari penelitian ini adalah apakah terdapat pengaruh jenis kecerdasan terhadap penguasaan matematika siswa khususnya topik Aljabar pada tingkat Madrasah Tsanawiyah (MTs)/ Sekolah Menengah Pertama (SMP).

\section{TINJAUA PUSTAKA}

Terminologi jenis kecerdasan disarikan dari istilah 'multiple intelligence' (kecerdasan berganda) yang dipakai oleh Howard Gardner (1983)'. Gardner memaparkan sembilan jenis kecerdasan yang dimiliki manusia meskipun setiap orang bisa memiliki kecenderungan untuk dominan pada satu, dua atau lebih yang bisa menentukan pencapaian seseorang dalam hidupnya. Jadi istilah jenis kecerdasan disini mengacu kepada pandangan atas keterkategorian kecerdasan tersebut, jadi bukan pada kebergandaannya.

Gardner dan Hatch (1989) ${ }^{2}$ dan Gardner (2009) ${ }^{3}$ memetakan ketujuh jenis kecerdasan utama antara lain kecerdasan logika/matematika, kecerdasan linguistik, kecerdasan musikal, kecerdasan spasial, kecerdasan bodily-kinestetik, kecerdasan interpersonal, dan kecerdasan intrapersonal.

\section{Hasil Belajar Topik Aljabar}

Hasil belajar menurut Bloom dibagi ke dalam tiga ranah (domain), yaitu kognitif, psikomotor, dan afektif. Sementara itu Gagne membagi hasil belajar

${ }^{1}$ Gardner, Howard. Howard Gardner's Theory of Multiple Intelligences. Retrieved from www.niu.edu on April 4, 2015.

${ }^{2}$ Gardner, H dan T. Hatch. Multiple Intelligences Go To School: Educational Implications of the Theory of Multiple Intelligences. Educational Researcher, Vol. 18, No. 8 (Nov., 1989). P.4-10., p.6

${ }^{3}$ Gardner, Howard. Howard Gardner's ........, p. 1-9 
atau kemampuan manusia menjadi 5 kategori, yaitu: informasi verbal, keterampilan intelektual, strategi kognitif, keterampilan motorik dan sikap. Jadi, hasil belajar matematika adalah suatu kemampuan yang diperoleh siswa setelah ia mempelajari matematika baik berupa pengetahuan, pemahaman maupun pengertian. Hasil belajar yang dimaksudkan dalam penelitian ini adalah hasil belajar siswa pada topik aljabar.

Berdasarkan kajian teori, penelitian yang relevan dan kerangka berfikir di atas maka hipotesis penelitian ini dirumuskan adalah:

$\mathrm{H}_{0}$ : Tidak terdapat perbedaan jenis kecerdasan terhadap hasil belajar topik aljabar siswa MTsN se-Kota Padangsidimpuan

$\mathrm{H}_{1}$ : Paling sedikit ada satu $\mu_{\mathrm{j}}$ yang tidak sama

\section{METODE PENELITIAN}

Jenis penelitian ini adalah penelitian ex post facto. Penelitian ini juga disebut penelitian kausal komparatif karena dimaksud untuk menyelidiki kausa yang mungkin untuk suatu pola prilaku yang dilakukan dengan cara membandingkan subjek dimana pola tersebut ada dengan subjek yang serupa dimana pola tersebut tidak ada atau berbeda.

Penelitian ini dilaksanakan di MTsN se Kota Padangsidimpuan yang terdiri dari MTsN 1 dan MTsN 2. MTsN 1 beralamat di Jl. Sutan Soripada Mulia dan MTsN 2 beralamat di Jl. T. Rizal Nurdin. Sedangkan waktu pelaksanaan penelitian ini dilaksanakan pada bulan April 2015 sampai dengan selesai. Populasi dalam penelitian ini adalah seluruh siswa MTsN se Kota Padangsidimpuan kelas VII semester II yang berstatus aktif TA. 2015/2016. Sampel dalam penelitian ini adalah seluruh siswa MTsN se Kota Padangsidimpuan kelas VII semester II yang berstatus aktif TA. 2015/2016. Oleh karena itu penelitian ini disebut juga dengan penelitian populasi. Untuk memperoleh data tentang jenis kecerdasan yang dimiliki oleh siswa, diberikan angket tentang jenis kecerdasan. Angket ini diadaptasi dari Teori Kecerdasan sebagaimana yang dijelaskan oleh Howard Gardner. Angket yang akan digunakan merupakan angket yang sudah terstandard. Kemudian untuk memperoleh data hasil belajar siswa pada topik aljabar maka diberikan test kepada seluruh teste.

Data yang terkumpul berdasarkan hasil test, kemudian dianalisis dengan menggunakan analisis variansi untuk melihat perbedaan hasil belajar siswa 
74 | TAZKIR: Jurnal Penelitian Ilmu-ilmu Sosial dan Keislaman

Vol. 02 No. 2 Desember 2016

dilihat dari kecenderungan jenis kecerdasannya. Apabila terdapat perbedaan pada salah satu jenis kecerdasan, maka akan dilanjutkan dengan uji post hoc.

\section{HASIL PENELITIAN DAN PEMBAHASAN}

\section{Kemampuan Siswa Menyelesaikan Topik Aljabar berdasarkan Kecerdasan}

Kemampuan siswa menyelesaikan topik aljabar berdasarkan jenis kecerdasan adalah sebagai berikut:

\section{Kecerdasan bahasa (linguistic intelligence)}

Siswa yang cenderung pada kecerdasan bahasa (linguistic intelligence) dari seluruh siswa kelas VIII MTsN 1 dan MTsN 2 se-Kota Padangsidimpuan yang telah diuji kemampuan menyelesaikan soal topik aljabar ditemukan sebanyak 19 siswa, didapatkan nilai perorangan, mean nilai keseluruhan, modus dan mediannya sebagai berikut:

\begin{tabular}{lll}
\hline No & Inisial Siswa & Nilai \\
\hline 1 & MH & 49,8 \\
\hline 2 & RH & 49,8 \\
\hline 3 & HS & 58,1 \\
\hline 4 & SS & 49,8 \\
\hline 5 & NM & 66,4 \\
\hline 6 & NF & 83 \\
\hline 7 & PA & 74,7 \\
\hline 8 & MHH & 74,7 \\
\hline 9 & NH & 83 \\
\hline 10 & SM & 66,4 \\
\hline 11 & BH & 83 \\
\hline 12 & SF & 83 \\
\hline 13 & SN & 74,7 \\
\hline 14 & AR & 66,4 \\
\hline 15 & AM & 74,7 \\
\hline 16 & YK & 83 \\
\hline 17 & FN & 66,4 \\
\hline 18 & IS & 58,1 \\
\hline 19 & IH & 58,1 \\
\hline Mean & 68,58 \\
\hline & & \\
\hline
\end{tabular}




\begin{tabular}{ll}
\hline Median & 66,4 \\
\hline Modus & 83,0 \\
\hline
\end{tabular}

\section{Kecerdasan logika-matematika (logical-mathematical intelligence)}

Siswa yang cenderung pada logika-matematika (logical-mathematical intelligence) dari seluruh siswa kelas VIII MTsN 1 dan MTsN 2 se-Kota Padangsidimpuan yang telah diuji kemampuan menyelesaikan soal topik aljabar ditemukan sebanyak 16 siswa, didapatkan nilai perorangan, mean nilai keseluruhan, modus dan mediannya sebagai berikut:

\begin{tabular}{lll}
\hline No & Inisial Siswa & Nilai \\
\hline 1 & SA & 66,4 \\
\hline 2 & RI & 74,7 \\
\hline 3 & SM & 74,7 \\
\hline 4 & AF & 41,5 \\
\hline 5 & IW & 66,4 \\
\hline 6 & AM & 100 \\
\hline 7 & AS & 91,3 \\
\hline 8 & MF & 74,7 \\
\hline 9 & WM & 66,4 \\
\hline 10 & MJ & 66,4 \\
\hline 11 & AH & 74,7 \\
\hline 12 & AA & 74,7 \\
\hline 13 & AR & 91,3 \\
\hline 14 & AP & 74,7 \\
\hline 15 & GP & 41,5 \\
\hline 16 & SA & 66,4 \\
\hline Mean & 71,6 \\
\hline Median & 74,7 \\
\hline Modus & 74,7 \\
\hline &
\end{tabular}

\section{Kecerdasan spasial (spatial intelligence)}

Siswa yang cenderung pada kecerdasan spasial (spatial intelligence) dari seluruh siswa kelas VIII MTsN 1 dan MTsN 2 se-Kota Padangsidimpuan yang telah diuji kemampuan menyelesaikan soal topik 
76 | TAZKIR: Jurnal Penelitian Ilmu-ilmu Sosial dan Keislaman

Vol. 02 No. 2 Desember 2016

aljabar ditemukan sebanyak 16 siswa, didapatkan nilai perorangan, mean nilai keseluruhan, modus dan mediannya sebagai berikut:

\begin{tabular}{lll}
\hline No & Inisial Siswa & Nilai \\
\hline 1 & AH & 66,4 \\
\hline 2 & NM & 74,7 \\
\hline 3 & AN & 74,7 \\
\hline 4 & FF & 74,7 \\
\hline 5 & DT & 58,1 \\
\hline 6 & SN & 33,2 \\
\hline 7 & AM & 83 \\
\hline 8 & RA & 91,3 \\
\hline 9 & DA & 83 \\
\hline 10 & JH & 74,7 \\
\hline 11 & MA & 33,2 \\
\hline 12 & NA & 58,1 \\
\hline 13 & DR & 91,3 \\
\hline 14 & RR & 58,1 \\
\hline 15 & SC & 66,4 \\
\hline 16 & FR & 74,7 \\
\hline Mean & $\mathbf{6 8 , 4 8}$ \\
\hline Median & $\mathbf{7 4 , 7}$ \\
\hline Modus & $\mathbf{7 4 , 7}$ \\
\hline
\end{tabular}

4. Kecerdasan badaniah-kinestetik (bodily-kinesthetic intelligence)

Siswa yang cenderung pada kecerdasan badaniah-kinestetik (bodily-kinesthetic intelligence) dari seluruh siswa kelas VIII MTsN 1 dan MTsN 2 se-Kota Padangsidimpuan yang telah diuji kemampuan menyelesaikan soal topik aljabar ditemukan sebanyak 12 siswa, didapatkan nilai perorangan, mean nilai keseluruhan, modus dan mediannya sebagai berikut:

\begin{tabular}{lll}
\hline No & Inisial Siswa & Nilai \\
\hline 1 & DY & 74,7 \\
\hline 2 & AS & 66,4 \\
\hline 3 & KS & 83 \\
\hline
\end{tabular}




\begin{tabular}{lll}
\hline 4 & CR & 66,4 \\
\hline 5 & RR & 74,7 \\
\hline 6 & AN & 74,7 \\
\hline 7 & RA & 74,7 \\
\hline 8 & RP & 58,1 \\
\hline 9 & NM & 83 \\
\hline 10 & AF & 74,7 \\
\hline 11 & YR & 66,4 \\
\hline 12 & ML & 58,1 \\
\hline Mean & $\mathbf{7 1 , 2 4}$ \\
\hline \multicolumn{2}{l}{ Median } & $\mathbf{7 4 , 7}$ \\
\hline \multicolumn{2}{l}{ Modus } & $\mathbf{7 4 , 7}$ \\
\hline
\end{tabular}

\section{Kecerdasan musikal (musical intelligence)}

Siswa yang cenderung pada kecerdasan musikal (musicalintelligence) dari seluruh siswa kelas VIII MTsN 1 dan MTsN 2 se-Kota Padangsidimpuan yang telah diuji kemampuan menyelesaikan soal topik aljabar ditemukan sebanyak 26 siswa, didapatkan nilai perorangan, mean nilai keseluruhan, modus dan mediannya sebagai berikut:

\begin{tabular}{lll}
\hline No & Inisial Siswa & Nilai \\
\hline 1 & AR & 49,8 \\
\hline 2 & AN & 58,1 \\
\hline 3 & RA & 66,4 \\
\hline 4 & ZH & 16,6 \\
\hline 5 & KN & 33,2 \\
\hline 6 & SS & 49,8 \\
\hline 7 & SA & 83 \\
\hline 8 & WA & 100 \\
\hline 9 & FA & 83 \\
\hline 10 & PN & 58,1 \\
\hline 11 & NA & 83 \\
\hline 12 & AA & 49,8 \\
\hline 13 & NS & 58,1 \\
\hline 14 & RA & 49,8 \\
\hline & &
\end{tabular}


78 | TAZKIR: Jurnal Penelitian Ilmu-ilmu Sosial dan Keislaman

Vol. 02 No. 2 Desember 2016

\begin{tabular}{lll}
\hline No & Inisial Siswa & Nilai \\
\hline 15 & AF & 49,8 \\
\hline 16 & SA & 49,8 \\
\hline 17 & HA & 16,6 \\
\hline 18 & FM & 49,8 \\
\hline 19 & WM & 8,3 \\
\hline 20 & DS & 66,4 \\
\hline 21 & FA & 49,8 \\
\hline 22 & MP & 66,4 \\
\hline 23 & FM & 58,1 \\
\hline 24 & MB & 58,1 \\
\hline 25 & IM & 74,7 \\
\hline 26 & AR & 74,7 \\
\hline Mean & $\mathbf{5 6 , 2}$ \\
\hline Median & $\mathbf{5 8 , 1}$ \\
\hline Modus & $\mathbf{4 9 , 8}$ \\
\hline
\end{tabular}

6. Kecerdasan interpersonal (interpersonal intelligence)

Siswa yang cenderung pada kecerdasan musikal (interpersonalintelligence) dari seluruh siswa kelas VIII MTsN 1 dan MTsN 2 se-Kota Padangsidimpuan yang telah diuji kemampuan menyelesaikan soal topik aljabar ditemukan sebanyak 14 siswa, didapatkan nilai perorangan, mean nilai keseluruhan, modus dan mediannya sebagai berikut:

\begin{tabular}{lll}
\hline No & Inisial Siswa & Nilai \\
\hline 1 & NT & 66,4 \\
\hline 2 & HH & 41,5 \\
\hline 3 & MF & 74,7 \\
\hline 4 & RH & 74,7 \\
\hline 5 & AP & 74,7 \\
\hline 6 & IA & 91,3 \\
\hline 7 & AR & 74,7 \\
\hline 8 & HA & 74,7 \\
\hline 9 & SI & 66,4 \\
\hline 10 & RA & 74,7 \\
\hline 11 & PF & 74,7 \\
\hline
\end{tabular}




\begin{tabular}{lll}
\hline No & Inisial Siswa & Nilai \\
\hline 12 & HA & 74,7 \\
\hline $13 \quad$ SK & 100 \\
\hline $14 \quad$ AH & 16,6 \\
\hline Mean & $\mathbf{6 9 , 9 9}$ \\
\hline Median & $\mathbf{7 4 , 7}$ \\
\hline Modus & $\mathbf{7 4 , 7}$ \\
\hline
\end{tabular}

\section{Kecerdasan intrapersonal (intrapersonal intelligence)}

Siswa yang cenderung pada kecerdasan musikal (intrapersonalintelligence) dari seluruh siswa kelas VIII MTsN 1 dan MTsN 2 se-Kota Padangsidimpuan yang telah diuji kemampuan menyelesaikan soal topik aljabar ditemukan sebanyak 17 siswa, didapatkan nilai perorangan, mean nilai keseluruhan, modus dan mediannya sebagai berikut:

\begin{tabular}{lll}
\hline No & Inisial Siswa & Nilai \\
\hline 1 & EY & 91,3 \\
\hline 2 & RF & 100 \\
\hline 3 & FS & 49,8 \\
\hline 4 & BS & 58,1 \\
\hline 5 & SS & 74,7 \\
\hline 6 & MR & 66,4 \\
\hline 7 & AH & 41,5 \\
\hline 8 & IP & 66,4 \\
\hline 9 & NA & 74,7 \\
\hline 10 & SA & 66,4 \\
\hline 11 & HD & 83 \\
\hline 12 & CM & 58,1 \\
\hline 13 & SK & 58,1 \\
\hline 14 & GA & 74,7 \\
\hline 15 & AM & 66,4 \\
\hline 16 & JH & 83 \\
\hline 17 & AH & 83 \\
\hline Mean & 70,33 \\
\hline Median & $\mathbf{6 6 , 4}$ \\
\hline Modus & $\mathbf{6 6 , 4}$ \\
\hline
\end{tabular}


80 | TAZKIR: Jurnal Penelitian Ilmu-ilmu Sosial dan Keislaman

Vol. 02 No. 2 Desember 2016

Dari deskripsi data di atas dapat diurutkan mean kemampuan menyelesaikan soal aljbar siswa MTsN se-Kota Padangsidimpuan menurut jenis kecerdasannya dari tertetinggi ke terendah sebagai berikut: Logika-matematika $(71,6)>$ Kinestetik $(71,24)>$ Intrapersonal $(70,33)>$ Interpersonal $(69,99)>$ Linguistik $(68,58)>$ Spasial $(68,48)>$ Musika $(56,2)$. Perbandingan mediannya adalah sebagai berikut: Logika-matematika $(74,7)=$ Kinestetik $(74,7)=$ Spasial $(74,7)=$ Interpersonal $(74,7)>$ Linguistik $(66,4)=$ Intrapersonal $(66,4)>$ Musikal $(58,1)$. Sedangkan perbandingan modusnya: Linguistik $(83,0)>$ Logikamatematika $(74,7)=$ Spasial $(74,7)=$ Kinestetik $(74,7)=$ Interpersonal $(74,7)>$ Intrapersonal $(66,4)>$ Musikal $(49,8)$. Selanjutnya dipresentasikan dengan urutan nilai mean sebagai berikut:

\begin{tabular}{|l|c|c|c|c|c|c|c|}
\hline \multicolumn{1}{|r|}{ Kcr' $^{\prime}$} & LogM & Kin & Ipa & Ipe & Ling & Spa & Mus \\
\hline Mean & 71,6 & 71,24 & 70,33 & 69,99 & 68,58 & 68,48 & 56,2 \\
\hline Median & 74,7 & 74,7 & 66,4 & 74,7 & 66,4 & 74,7 & 58,1 \\
\hline Modus & 74,7 & 74,7 & 66,4 & 74,7 & 83,0 & 74,7 & 49,8 \\
\hline
\end{tabular}

\section{Pengujian hipotesis}

\section{Uji Persyaratan}

Parameter yang dipakai untuk sebelum melakukan uji Anova adalah normalitas dan homogenitas. Dengan menggunakan rumus KolmogorovSmirnov dalam aplikasi SPSS versi 17 hasil uji normalitas kelompokkelompok jenis kecerdasan adalah sebagai berikut:

a) Kecerdasan linguistik (linguistic intelligence)

Descriptive Statistics

\begin{tabular}{|l|r|r|r|r|r|}
\hline & N & Mean & Std. Deviation & Minimum & Maximum \\
\hline Nilai & 19 & 68.584 & 12.0094 & 49.8 & 83.0 \\
\hline
\end{tabular}

One-Sample Kolmogorou-Smirnou Test

\begin{tabular}{|ll|r|}
\hline & & \multicolumn{1}{|c|}{ Nilai } \\
\hline Normal Parametersa..b & Mean & 19 \\
& Std. Deviation & 68.584 \\
Most Extreme Differences & 12.0094 \\
& Absolute & .168 \\
& Positive & .124 \\
Kolmogorov-Smirnov $Z$ & Negative & -.168 \\
Asymp. Sig. (2-tailed) & & .734 \\
\hline
\end{tabular}

a. Test distribution is Normal.

b. Calculated from data. 
Berdasarkan hasil uji tersebut maka kemampuan para siswa yang memiliki kecerdasan linguistik berdistribusi normal pada taraf signifikansi $\alpha=0,05$., diperoleh sig.0,654>0,05.

b) Kecerdasan logika-matematika (logical-mathematical intelligence)

Descriptine Statistics

\begin{tabular}{|l|r|r|r|r|r|}
\hline & N & Mean & Std. Deviation & Minimum & Maximum \\
\hline Nilai & 16 & 71.613 & 15.4653 & 41.5 & 100.0 \\
\hline
\end{tabular}

One-Sample Kolmogorow-Smirnow Test

\begin{tabular}{|ll|r|}
\hline & & \multicolumn{1}{|c|}{ Nilai } \\
\hline Normal Parametersa..b & Mean & 16 \\
& Std. Deviation & 71.613 \\
Most Extreme Differences & 15.4653 \\
& Absolute & .243 \\
& Positive & .233 \\
Kolmogorov-Smirnov $Z$ & Negative & -.243 \\
Asymp. Sig. (2-tailed) & & .972 \\
\hline
\end{tabular}

a. Test distribution is Normal.

b. Calculated from data.

Berdasarkan hasil uji tersebut maka kemampuan para siswa yang memiliki kecerdasan logika-matematika berdistribusi normal pada taraf signifikansi $\alpha=0,05$., diperoleh sig.0,301>0,05.

c) Kecerdasan spasial (spatial intelligence)

Descriptime Statistics

\begin{tabular}{|l|r|r|r|r|r|}
\hline & N & Mean & Std. Deviation & Minimum & Maximum \\
\hline Nilai & 16 & 68.475 & 17.2778 & 33.2 & 91.3 \\
\hline
\end{tabular}

One-Sample Kolmogorov-Smirnow Test

\begin{tabular}{|ll|r|}
\hline & & \multicolumn{1}{|c|}{ Nilai } \\
\hline Normal Parametersa..b & Mean & 16 \\
& Std. Deviation & 68.475 \\
Most Extreme Differences & 17.2778 \\
& Absolute & .203 \\
& Positive & .109 \\
Kolmogorov-Smirnov $Z$ & Negative & -.203 \\
Asymp. Sig. (2-tailed) & & .813 \\
\hline
\end{tabular}

a. Test distribution is Normal.

b. Calculated from data.

Berdasarkan hasil uji tersebut maka kemampuan para siswa yang memiliki kecerdasan spasial berdistribusi normal pada taraf signifikansi $\alpha=0,05$., diperoleh sig.0,524>0,05. 
82 | TAZKIR: Jurnal Penelitian Ilmu-ilmu Sosial dan Keislaman

Vol. 02 No. 2 Desember 2016

d) Kecerdasan badaniah-kinestetik (bodily-kinesthetic intelligence)

Descriptime Statistics

\begin{tabular}{|l|r|r|r|r|r|}
\hline & N & Mean & Std. Deviation & Minimum & Maximum \\
\hline Nilai & 12 & 71.242 & 8.2685 & 58.1 & 83.0 \\
\hline
\end{tabular}

One-Sample Kolmogorov-Smirnow Test

\begin{tabular}{|ll|r|}
\hline & & \multicolumn{1}{|c|}{ Nilai } \\
\hline Normal Parametersa..b & Mean & 12 \\
& Std. Deviation & 71.242 \\
Most Extreme Differences & 8.2685 \\
& Absolute & .245 \\
& Positive & .171 \\
Kolmogorov-Smirnov $Z$ & Negative & -.245 \\
Asymp. Sig. (2-tailed) & & .850 \\
\hline
\end{tabular}

a. Test distribution is Normal.

b. Calculated from data.

Berdasarkan hasil uji tersebut maka kemampuan para siswa yang memiliki kecerdasan badaniah-kinestetik berdistribusi normal pada taraf signifikansi $\alpha=0,05$., diperoleh sig.0,465>0,05.

e) Kecerdasan musikal (musical intelligence)

Descriptive Statistics

\begin{tabular}{|l|r|r|r|r|r|}
\hline & \multicolumn{1}{|c|}{$N$} & Mean & Std. Deviation & Minimum & Maximum \\
\hline Nilai & 26 & 56.200 & 21.3310 & 8.3 & 100.0 \\
\hline
\end{tabular}

One-Sample Kolmogorow-Smirnow Test

\begin{tabular}{|ll|r|}
\hline & & \multicolumn{1}{c|}{ Nilai } \\
\hline Normal Parametersa.,b & Mean & 26 \\
& Std. Deviation & 56.200 \\
Most Extreme Differences & 21.3310 \\
& Absolute & .228 \\
& Positive & .118 \\
Kolmogorov-Smirnov $Z$ & Negative & -.228 \\
Asymp. Sig. (2-tailed) & & 1.164 \\
\hline
\end{tabular}

a. Test distribution is Normal.

b. Calculated from data.

Berdasarkan hasil uji tersebut maka kemampuan para siswa yang memiliki kecerdasan musikal berdistribusi normal pada taraf signifikansi $\alpha=0,05$., diperoleh sig.0,133>0,05. 
f) Kecerdasan interpersonal (interpsersonal intelligence)

Descriptime Statistics

\begin{tabular}{|l|r|r|r|r|r|}
\hline & N & Mean & Std. Deviation & Minimum & Maximum \\
\hline Nilai & 14 & 69.986 & 20.0387 & 16.6 & 100.0 \\
\hline
\end{tabular}

\begin{tabular}{|c|c|c|}
\hline & & Nilai \\
\hline $\mathrm{N}$ & & 14 \\
\hline \multirow[t]{2}{*}{ Normal Parameters a..b } & Mean & 69.986 \\
\hline & Std. Deviation & 20.0387 \\
\hline \multirow[t]{3}{*}{ Most Extreme Differences } & Absolute & .307 \\
\hline & Positive & .264 \\
\hline & Negative & -.307 \\
\hline Kolmogorov-Smirnov $Z$ & & 1.150 \\
\hline Asymp. Sig. (2-tailed) & & .142 \\
\hline
\end{tabular}

a. Test distribution is Normal.

b. Calculated from data.

Berdasarkan hasil uji tersebut maka kemampuan para siswa yang memiliki kecerdasan interpersonal berdistribusi normal pada taraf signifikansi $\alpha=0,05$., diperoleh sig.0,142>0,05.

g) Kecerdasan intrapersonal (intrapersonal intelligence)

Descriptive Statistics

\begin{tabular}{|l|r|r|r|r|r|}
\hline & \multicolumn{1}{|c|}{$\mathrm{N}$} & Mean & Std. Deviation & Minimum & Maximum \\
\hline Nilai & 17 & 70.329 & 15.0459 & 41.5 & 100.0 \\
\hline
\end{tabular}

One-Sample Kolmogorow-Smirnow Test

\begin{tabular}{|ll|r|}
\hline & & \multicolumn{1}{|c|}{ Nilai } \\
\hline N & & 17 \\
Normal Parametersa..b & Mean & 70.329 \\
& Std. Deviation & 15.0459 \\
Most Extreme Differences & .132 \\
& Absolute & .132 \\
& Positive & -.103 \\
Kolmogorov-Smirnov $Z$ & Negative & .546 \\
Asymp. Sig. (2-tailed) & & .927 \\
\hline
\end{tabular}

a. Test distribution is Normal.

b. Calculated from data.

Berdasarkan hasil uji tersebut maka kemampuan para siswa yang memiliki kecerdasan interpersonal berdistribusi normal pada taraf signifikansi $\alpha=0,05$., diperoleh sig.0,927>0,05.

Selanjutnya hasil uji homogenitas dengan menggunakan rumus One way-Anova dalam applikasi SPSS versi 17, disajikan deskripsi data dan hasil ujinya sebagai berikut: 
84 | TAZKIR: Jurnal Penelitian Ilmu-ilmu Sosial dan Keislaman

\section{Descriptives}

\begin{tabular}{l} 
N| rilai \\
\hline
\end{tabular}

Test of Homogeneity of Variances

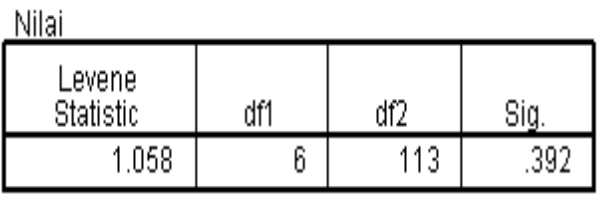

Berdasarkan hasil uji tersebut maka kemampuan para siswa yang telah di -test dari seluruh jenis kecerdasan variansinya dinyatakan homogen pada taraf signifikansi $\alpha=0,05$., diperoleh sig.0,392>0,05.

Uji Hipotesis

Pengujian dilakukan terhadap hipotesis penelitian berbunyi:

$\mathrm{H}_{0}$ : Tidak terdapat perbedaan jenis kecerdasan terhadap hasil belajar topik aljabar siswa MTsN se-Kota Padangsidimpuan

$\mathrm{H}_{1}$ : Paling sedikit ada satu $\mu_{\mathrm{j}}$ yang tidak sama

Dengan menggunakan One way-Anova terhadap data yang telah dideskripsikan di atas dengan aplikasi SPSS versi 17 diperoleh hasil sebagai berikut:

\section{ANOVA}

\begin{tabular}{|c|c|c|c|c|c|}
\hline & $\begin{array}{l}\text { Sum of } \\
\text { Squares }\end{array}$ & df & Mean Square & $\mathrm{F}$ & Sig. \\
\hline Between Groups & 3984.552 & 6 & 664.092 & \multirow[t]{3}{*}{2.372} & \multirow[t]{3}{*}{.034} \\
\hline Within Groups & 31631.034 & 113 & 279.921 & & \\
\hline Total & 35615.587 & 119 & & & \\
\hline
\end{tabular}


Berdasarkan hasil uji tersebut maka terdapat perbedaan kemampuan menyelesaikan soal topik aljabar siswa kelas VIII MTsN seKota Padangsidimpuan pada taraf signifikansi $\alpha=0,05$., diperoleh $\mathrm{F}_{\text {hitung }}$ $=2,372>\mathrm{F}_{\text {tabel }}$ 2,09, berarti ditolak $\mathrm{H}_{0}$ dan $\mathrm{H}_{1}$ diterima.

Setelah ditolah $\mathrm{H}_{0}$ maka dilakukan uji lanjut untuk menentukan urutan perbedaan kemampuan menyelesaikan soal aljabar siswa kelas VIII MTsN se-Kota Padangsidimpuan. Untuk itu dilakukan uji Post-Hoc dengan menggunakan uji-Scheffe, hasilnya adalah sebagai berikut:

\section{Homogeneous Subsets}

\begin{tabular}{|c|c|c|}
\hline \multicolumn{3}{|c|}{ Nilai } \\
\hline Scheffe ${ }^{a, . b}$ & & \\
\hline \multirow[b]{2}{*}{ Kecerdasan } & \multirow[b]{2}{*}{ N } & $\begin{array}{c}\text { Subset for } \\
\text { alpha }=0.05\end{array}$ \\
\hline & & 1 \\
\hline$E$ & 26 & 56.2000 \\
\hline $\mathrm{c}$ & 16 & 68.4750 \\
\hline A & 19 & 68.5842 \\
\hline $\mathrm{F}$ & 14 & 69.9857 \\
\hline$G$ & 17 & 70.3294 \\
\hline D & 12 & 71.2417 \\
\hline B & 16 & 71.6125 \\
\hline Sig. & & .337 \\
\hline
\end{tabular}

Dari hasil di atas dapat diterangkan bahwa perbedaan hasil kemampuan menyelesaikan soal topik aljabar terjadi dengan urutan Logika-matematika> Badaniah-kinestetik> Intrapersonal $>$ Interpersonal $>$ Linguistik> Spasial $>$ Musikal.

Hasil penelitian yang telah dilakukan menguatkan kembali teori yang digagas oleh Howard Gardner (1983) bahwa terdapat tujuh jenis kecerdasan yang dimiliki oleh manusia. Lebih dari itu, penelitian juga telah menemukan jenjang kemampuan siswa dari tinggi ke rendah dalam hal menyelesaikan soal matematika secara umum dan aljabar pada khsusnya menurut jenis kecerdasannya memiliki urutan sebagai berikut: Logikamatematika > Badaniah-kinestetik> Intrapersonal $>$ Interpersonal $>$ Linguistik> Spasial> Musikal.

Oleh karena itu hasil penelitian ini juga menguatkan penelitian yang telah dilakukan oleh Ozlem Dogan Temur (2007), Jingchen Xie dan Ruilin Lin 
86 | TAZKIR: Jurnal Penelitian Ilmu-ilmu Sosial dan Keislaman

Vol. 02 No. 2 Desember 2016

(2009) dan Sibel Gurbuzoglu Yalmanci dan Ali Ibrahim Can Gozum (2013) yang berupaya untuk mereformasi proses pembelajaran dan evaluasi konvensional ke arah proses pembelajaran dan evaluasi yang berbasis kecerdasan berganda. Dalam artian bahwa pembelajaran dan evaluasi pendidikan yang dilaksanakan oleh guru seharusnya bernuansa/ didasarkan pada jenis kecerdasan yang dimiliki oleh siswa.

\section{PENUTUP}

Berdasarkan hasil penelitian ini ditemukan bahwa terdapat perbedaan kemampuan menyelesaikan soal topik aljabar siswa kelas VIII MTsN se-Kota Padangsidimpuan dilihat dari jenis kecerdasan siswa. Untuk melihat jenjang jenis kecerdasan selanjutnya dilakukan uji Post-Hoc dengan menggunakan ujiScheffe.

Dari hasil analisis dapat diterangkan bahwa perbedaan hasil kemampuan menyelesaikan soal topik aljabar terjadi dengan urutan Logika-matematika> Badaniah-kinestetik $>$ Intrapersonal $>$ Interpersonal $>$ Linguistik $>$ Spasial $>$ Musikal. 


\section{DAFTAR RUJUKAN}

Brown, Douglas H. Strategies for Success. New York: Longman, 2002

Chislett, V. and A Chapman. Multiple Intelligences Test - based on Howard Gardner's MI Model. Retrieved from www.businessball.com on March 2, 2015

Dannenhoffer, Joan V. dan Robert J. Radin. Using Multiple Intelligence Theory in Mathematic Classroom. A paper presented in a seminar at Ward College of Technology at The University of Hartford, 1998

Gardner, H dan T. Hatch. Multiple Intelligences Go To School: Educational Implications of the Theory of Multiple Intelligences. Educational Researcher, Vol. 18, No. 8 (Nov., 1989).

Gardner, Howard. Frames of Mind: The Theory of Multiple Intelligences. New York: Basic Books, 1983

Gardner, Howard. Howard Gardner's Theory of Multiple Intelligences. Retrieved from www.niu.edu on April 4, 2015

Munro, John. Multiple Intelligences and Mathematics Teaching. Paper presented at the Annual Conference of the Australian Remedial Mathematical Education Association., 1994., p. 2

Temur, Ozlem Dogan. The Effects of Teaching Activities Prepared According to the Multiple Intelligence Theory on Mathematics Achievements and Permanence of Information Learned by $4^{\text {th }}$ Grade Students. International Journal of Environmental \& Science Education, 2007, 2(4), 86 - 91

Xie, Jingchen dan Ruilin Lin. Research on Multiple Intelligences Teaching and Assessment. Asian Journal of Management and Humanity Sciences, Vol. 4, No. 2-3, pp. 106-124, 2009 
88 | TAZKIR: Jurnal Penelitian Ilmu-ilmu Sosial dan Keislaman Vol. 02 No. 2 Desember 2016

Strategi Reflektif dan Transinternal sebagai upaya Menumbuhkan Penghayatan Siswa dalam Pembelajaran PAI 